\title{
Mitochondrial dysfunction in cancer
}

\author{
Kinga Księżakowska-Łakoma ${ }^{1}$, Monika Żyła ${ }^{1}$, Jacek R. Wilczyński ${ }^{1,2}$ \\ ${ }^{1}$ Department of Gynecology, Chair of Obstetrics \& Gynecological Surgery, Medical University of Lodz, Lodz, Poland \\ 2Department of Gynecology and Oncologic Gynecology, “Polish Mother's Health Center” Research Institute, Lodz, Poland
}

\begin{abstract}
Mitochondria are semi-autonomous organelles of eukaryotic cells. They perform crucial functions such as generating most of the cellular energy through the oxidative phosphorylation (OXPHOS) system and some other metabolic processes. In addition, mitochondria are involved in regulation of cell death and reactive oxygen species (ROS) generation. Also, mitochondria play important roles in carcinogenesis via altering energy metabolism, resistance to apoptosis, increase of production of ROS and mtDNA (mitochondrial genome) changes. Studies have suggested that aerobic glycolysis is high in malignant tumors. Probably, it correlates with high glucose intake of cancerous tissues. This observation is contrary to Warburg's theory that the main way of energy generation in cancer cells is non-oxidative glycolysis. Further studies have suggested that in tumor cells both oxidative phosphorylation and glycolysis were active at various rates.

An increase of intracellular oxidative stress induces damage of cellular structure and somatic mutations. Further studies confirmed that permanent activity of oxidative stress and the influence of chronic inflammation damage the healthy neighboring epithelium and may lead to carcinogenesis. For instance, chronic inflammatory bowel disease could be related to high risk of colon adenocarcinoma.

The data have shown a role of ROS generation, mtDNA or nDNA alterations and abnormal apoptotic machinery in endometrial cancer progress. Recent studies suggest that mtDNA mutations might play a potential role in endometrial cancer progress and indicate an increase of mitochondrial biogenesis in this cancer. The investigators suggested that MtCOI and MtND6 alteration has an influence on assembly of respiratory complexes in endometrial cancer.

In many human cancers, there is a deregulation of the balance between cell growth and death. The tumor cells can avoid apoptosis through a loss of balance between anti- and pro-apoptotic proteins, reduced caspase function and impaired death receptor signaling. Over-expression of the anti-apoptotic BCL-2 gene has also been identified in numerous cancers including colon, thyroid, breast and endometrial cancer. Most studies have found low BCL-2 family gene expression, which could be a sign of blocking apoptosis in breast and endometrial cancer. Moreover, BCL-2 gene expression is correlated with the degree of aggressiveness and differentiation in endometrial cancer. As a result, it could be a valuable predictor of disease progression.
\end{abstract}

Key words: mitochondrium, cancer, oxidative stress, carcinogenesis, defective apoptotic pathways, inflammation.

\section{Mitochondrial structure}

Mitochondria are semi-autonomous, oval-shaped organelles of eukaryotic cells. On average, each human cell contains between a hundred and a thousand mitochondria. Cells that have a greater demand for ATP (adenosine-5'-triphosphate) such as hepatic cells, muscular or gastric gland cells and nerve cells contain about 1-2 thousand mitochondria [1-3]. Structurally, mitochondria possess five compartments: the inner and outer membrane, inter-membrane space, cristae and matrix (the region within the inner membrane). The outer membrane contains multiple copies of porin, which is permeable to small molecules. Larger proteins can enter mitochondria if they bind to translocase proteins of the outer membrane. The inner membrane is impermeable to most molecules. The transfer of molecules requires special membrane transporters. In addition, the inner membrane contains five types of proteins: respiratory chain protein, ATP synthase, protein import machinery, specific transport proteins that regulate metabolite passage into and out of the matrix, and mitochondria fusion and fission protein [1, 2]. The surface area of the inner membrane is compartmentalized into numerous cristae which can affect chemiosmotic function. The matrix is the space inside the 
inner mitochondrial membrane where most of the citric acid cycle activities and fatty acid oxidation take place $[4,5]$. Mitochondria perform essential functions in generating most of the cellular energy through the oxidative phosphorylation (OXPHOS) system and important metabolic intermediates in various pathways such as amino acids, fatty acids and carbohydrates. In addition, mitochondria are involved in the regulation of cell death and ROS (reactive oxygen species) generation [6-10].

Also, mitochondria play compelling roles in carcinogenesis via altered energy metabolism, resistance to apoptosis, increased production of ROS and mtDNA (mitochondrial genome) changes [11-14].

\section{Mitochondrial energy metabolism in cancer cells}

Under normoxic conditions normally cells rely on aerobic respiration through oxidation of glucose, fatty acids and amino acids. The glucose enters the cell via specific transporters and it is partially oxidized to pyruvate in the cytosol. Subsequently, the pyruvate can enter the mitochondria to fully undergo oxidation through the Krebs cycle and beta oxidation. The final products of tricarboxylic acid are two GTP (guanosine-5'-triphosphate) or ATP (adenosine-5'-triphosphate), six NADH (reduced form of nicotinamide adenine dinucleotide), two fumarate ubiquinol and four carbon dioxide molecules [14]. Aerobic respiration is the most efficient method of energy generation in cells. Nevertheless, under hypoxic conditions energy generation occurs through the cytosolic process. In the glycolysis process glucose is converted to pyruvate, and then pyruvate is reduced to lactate by $\mathrm{NADH}$. This process is less effective than OXPHOS [15].

The first interest in tumor energy metabolism was brought by the work of Otto Warburg. According to Warburg's observations, normal cells use lactic acid fermentation only in anaerobic conditions while cancer cells show an increased level of lactic acid production even under normal oxygen tension. Besides, Warburg proposed a model of defect in the OXPHOS pathway which stimulates the increase of lactic acid fermentation in tumor cells $[15,16]$. As a result, malignant cells produce their energy via a glycolytic mechanism rather than through the electron transport chain. Other works have suggested that aerobic glycolysis is high in malignant tumors. Probably, it correlates with high glucose intake of cancerous tissues such as gliomas, meningiomas and sarcomas [16-20]. Further studies have supposed that inside tumor cells both oxidative phosphorylation and glycolysis were active at various rates [21]. For instance, in MCF-7 cells originating from a mammary gland epithelial adenocarcinoma, the contribution of OXPHOS to the total cellular energy is $80 \%$ [22].

Anaerobic glycolysis is not a prerequisite of all tumor cells but could be a response to micro-environmen- tal conditions such as hypoxia which is observed inside the solid tumors or to glucose limitation. Additionally, the glycolysis advantage in cancer cells could be acquired during the highest proliferation. This observation is contrary to Warburg's theory that the main way of energy generation in cancer cells is non-oxidative glycolysis [23].

\section{Oxidative stress}

Oxidative stress reflects an imbalance between the production of reactive species (RS) and antioxidant defenses and leads to an increase in cellular levels of RS [24, 25]. Reactive species are chemically reactive molecules including reactive oxygen species (ROS). Examples include superoxide anion, hydrogen peroxide, and hydroxyl radical. Another group of RS consists of reactive nitrogen species (RNS) such as nitric oxide and nitrogen oxide radicals and reactive halogen or sulfur species $[24,26,27]$. The major source of ROS is mitochondria, where they are produced as a consequence of aerobic respiration and OXPHOS. Another endogenous source of reactive oxygen species is their production by neutrophils, eosinophils, macrophages and peroxisomes. ROS could also be produced through an exogenous way including chlorinated compounds, radiation, metal ions, hormone therapy, smoke and ethanol. Physiological roles of ROS include the effect on vascular tonus, platelet adhesion, regulating proliferation, gene transcription and metabolism [25, 28-31]. For instance, one of the RS, hydrogen peroxide $\left(\mathrm{H}_{2} \mathrm{O}_{2}\right)$, acts as an important intracellular messenger, and regulates apoptosis and senescence $[29,30]$.

Reactive oxygen species are eliminated by protective mechanisms, referred to as antioxidants. Antioxidant mechanisms operate through both enzymatic and non-enzymatic mitochondrial components, cellular membrane and extracellulary. The mitochondrial enzymatic defenses include manganese-superoxide dismutase (MnSOD2), glutathione peroxidase (GPX), glutathione reductase (GRed), peroxiredoxins, glutaredoxins and proteins such as cytochrome c. The nonenzymatic defenses are reduced glutathione (GSH), and high $N A D(P) I / N A D(P)$ ratio [32]. SOD2 is one of the most effective antioxidant enzymes. It has antitumor activity too. Therefore, over-expression of manganesesuperoxide dismutase leads to tumor growth retardation in several cell lines $[33,34]$. The cellular membrane antioxidant mechanisms include vitamin E, $\beta$-carotene, and coenzyme $\mathrm{Q}$. Thirdly, there is an extracellular mechanism including metal-binding proteins, bilirubin and vitamin $C$ and extracellular forms of glutathione peroxidases and superoxide dismutases [27].

An increase of intracellular oxidative stress induces damage of cellular structure and somatic mutations, leading to cancerous transformation. Moreover, senes- 
cence causes an increase of intracellular oxidative stress and a decrease of antioxidants and accumulation of molecular damage in DNA. These processes, nascent as a result of aging, can lead to an increase of the risk of mutagenesis [35-37].

In cancer cells, ROS generation is often increased. This could be the effect of exposure to the hypoxic micro-environment inside the tumor. This increase may contribute to induction of mtDNA alterations. Cells counteract the destructive effects of ROS increase; therefore, they imply genomic instability. For instance, the hydroxyl radical could activate oncogenes or inactivate tumor suppressor genes and prevent DNA repair $[28,38]$. MtDNA mutations correlate with the highest level of antioxidant enzymes such as CAT and PRX3 in endometrial cancer. It could be suggested that mtDNA mutations contribute to increased ROS generation, as a result, leading to compensatory antioxidant mechanisms [39].

The studies suggest that secular inflammation could predispose the host to an increased risk of cancers [40]. For instance, chronic inflammatory bowel disease could be related to high risk of colon adenocarcinoma or chronic pancreatitis may lead to an increased risk of pancreatic cancer [41, 42]. Rudolf Virchow was the first to get interested in the influence of chronic inflammation for cancer development. He demonstrated the presence of inflammatory cells within tumors and growth of tumor as a result of maintaining chronic inflammation [43]. Further studies confirmed that the permanent influence of chronic inflammation and activity of oxidative stress damage the healthy neighboring epithelial and stromal cells and they may lead to carcinogenesis. Inflammatory cells produce essential mediators such as cytokines, chemokines and metabolites of arachidonic acid which activate signal transduction cascades. These mediators also induce alterations in transcription factors including nuclear factor kappa B (NF- $\mathrm{BB})$, signal transducer and activator of transcription 3 (STAT3), hyp-

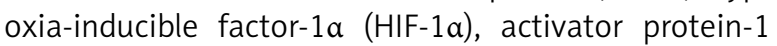
(AP-1), nuclear factor of activated T cells (NFAT) and NF-E2 related factor-2 (Nrf-2). They are directly responsible for activation of oxidative stress responses. These processes can activate genetic and epigenetic alterations such as point mutations in tumor suppressor genes, DNA methylation and post-translational modifications, causing changes in essential cellular pathways leading to cancer development [44, 45]. In addition, the effect of oxidative stress and chronic inflammation may influence the tumor cell transformation, promotion, survival, proliferation, invasion, and metastasis progression, and regulate angiogenesis [46-49]. ROS may cause DNA damage leading to genetic lesions that initiate carcinogenicity. Similarly, inflammatory cells such as neutrophils could also increase DNA damage via activating substances including aromatic amines, aflatoxins, estrogens, phenols, and polycyclic aromatic hydrocarbons by ROS-dependent mechanisms. ROS and genomic instability can also activate certain signaling pathways and thus they contribute to cancerous proliferation, angiogenesis and metastasis [50-53]. On the other hand, ROS can perform a role of anti-tumorigenic agents through the induction of cellular aging and cell death [54].

Oxidative status has been reported to play a role in NF- $\kappa B$ regulation. NF- $\kappa B$ influences the regulation of several genes involved in tumor development [55]. The role of ROS in activation of NF-kB is still unknown. Some studies suggest that ROS are indirect messengers in activation of NF- $\kappa B$ by TNF and IL-1. It is reported that TNF and IL-1 suppression leads to downregulation of the expression of active NF- $\mathrm{kB}$ and could inhibit proliferation of lymphoma and myelogenous leukemia cells $[56,57]$. Inhibition or activation of NF- $\mathrm{kB}$ is dependent on intensity of oxidative stress [58].

Reactive oxygen species are also reported to enhance tumor invasion and metastasis. Cancerous cells modify their morphology and adhesive mode, losing their normal epithelial polarization and differentiation. Then, these cells increase mobility, changing their phenotype to an invasive phenotype [59]. Oxidative stress can also activate the expression of intercellular adhesion protein-1 (ICAM-1), which regulates the transendothelial migration of neutrophils together with IL-8. It could play a potential role in tumor metastasis [60].

Some investigators report that the increase of expression of the matrix metalloproteinases (MMPs) could correlate with the invasion and metastasis of malignant tumor of different histogenetic origin. One of the MMP subgroups, gelatinase (MMP-2 and -9), plays a critical role in tumor invasion and metastasis. Their activation is high under prolonged oxidative stress [61].

Solid tumors induce an angiogenic response under the influence of stress factors such as hypoxia, nutrient deficiency and ROS. Tumoral angiogenesis is controlled by angiogenic factors including vascular endothelial growth factor (VEGF), fibroblast growth factor (FGF), and platelet-derived growth factor (PDGF) released by tumor and inflammatory cells in response to ROS production $[62,63]$. The release of VEGF causes a massive signaling cascade in endothelial cells that leads to an increasing number of blood vessels $[64,65]$.

\section{Mitochondrial DNA alteration}

Mitochondria possess their own genome (mtDNA) which is inherited only through the mother. The mtDNA is located in the mitochondrial matrix and it is a circular, double-stranded molecule of 16,569 base pairs in length containing 37 genes. These genes encode 13 polypeptides of the enzyme complexes of the electron transport chain, 2 ribosomal ribonucleic acid (rRNA) 
molecules (12S, 16S) (2 genes), and transfer tRNA molecules (22 genes) for protein synthesis $[66,67]$. In addition, mtDNA includes the displacement loop (D-loop), which is the major control region for replication and transcription of mtDNA. In this region it mutates several hundred times more frequently than other mtDNA regions $[68,69]$. High susceptibility of mtDNA to mutation is caused by being in close proximity to ROS generated by OXPHOS, an inefficient repair system, and lack of protective histones and introns. Therefore, mtDNA is more susceptible to alterations than nuclear DNA [7].

So far, we know several germlines and somatic mtDNA mutations that might be associated with various types of cancer. Recent studies suggested that most mtDNA alterations are located in the D-loop region. The D-loop contains the control region for replication and transcription of mtDNA. Therefore, mutations in this region might contribute to increase in the alterations in mtDNA gene expression. Furthermore, mtDNA mutations may cause OXPHOS deregulation and other components of mitochondrial metabolism leading to induction of the oncocytic phenotype [71, 72]. Nevertheless, the direct influence of mtDNA mutations on progression and side-effects of tumorigenesis is still a matter of debate.

Recent mtDNA mutations studies suggest their potential role in endometrial cancer progression and indicate an increase of mitochondrial biogenesis in this cancer. Guerra et al. investigated 23 type I endometrial cancer (EC) samples and matched typical hyperplasia for changes in mtDNA and in canonical nuclear genes (PTEN, KRAS, CTNNB1, TP53). All mtDNA alterations found in hyperplasia and EC samples were concurrent with mutations found in oncosuppressors/oncogenes (PTEN, KRAS, CTNNB1, TP53). Nevertheless, mtDNA mutational events occurred more frequently than nuclear mutations in the same cases. It could be indicated that mtDNA changes were first, followed by genetic instability of canonical genes involved in progression from hyperplasia to neoplasia. MtDNA base alterations were found in coding and non-coding regions. The investigators suggested that MtCOI nonsense change and frameshift alteration in MtND6 have an influence on assembly of respiratory complexes in endometrial cancer. They also claimed a correlation between mtDNA alterations and oncocytic histological features in type I endometrial cancer [39].

Liu et al. investigated mtDNA mutations in primary endometrial carcinomas, revealing high frequency of mitochondrial genome instability. Most of them were observed in the D-loop region as a hot-spot region for the majority of cancers. One particular alteration, mt$\mathrm{MSI}$, that frequently occurred in endometrial cancer samples may provide an important tool for endometrial cancer detection [73]. Polymorphisms in endometrial cancer are also mainly located in the D-loop region.

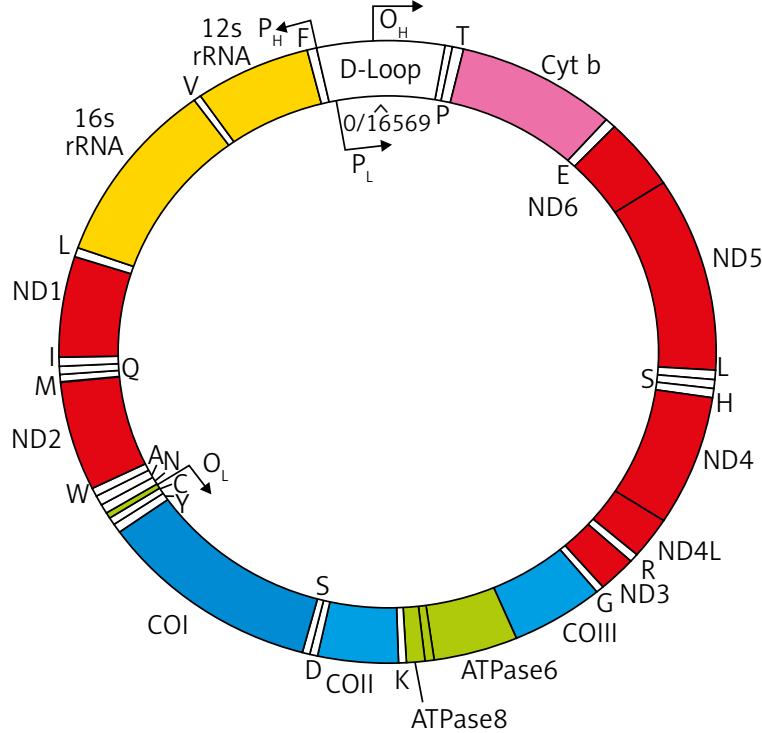

Fig. 1. Mitochondrial genome [70]

The data have suggested specific polymorphisms in the D-loop observed in endometrial cancer such as 16189T>C, 16223C, 207A, and 16126C. Investigators claim that the correlation between polymorphism and endometrial cancer development is high in 16223C/207A genotype. Studies have also suggested the correlation between a specific polymorphism and higher or lower risk of cancer. It is reported that A10398G and T16519C polymorphisms contribute to increased breast cancer risk in European-American females. Conversely, T3197C and G13708A polymorphisms are associated with reduced breast cancer risk in the same group of women [74]. Therefore, mtDNA polymorphism pattern could be useful as a diagnostic marker to select a population at high risk of developing cancer $[75,76]$.

Furthermore, several factors including estrogens, cigarette smoking, alcohol consumption and caloric intake could induce mitochondrial dysfunction and lead to high risk of breast cancer [77]. The estrogens correlate with breast cancer development through induction of mitochondrial transcription and generation of local ROS during normal metabolism of estradiol [78]. Investigators have also reported that smoking induces increase of mtDNA copy number in response to oxidative damage and could be associated with breast cancer risk [79-81]. Alcohol consumption also correlates with breast cancer development only when it is simultaneously associated with A10398G polymorphism occurrence [82]. Also, life style in combination with type of mtDNA polymorphism might influence cancerous disease development [83].

As mentioned above, mitochondrial DNA alterations have been observed in human cancers. The studies demonstrated that mitochondrial alterations may enable the early detection of cancer, and might contribute to development of a screening system and matching chemo- 
or radiotherapy $[81,84-86]$. The breast cancer studies have suggested a lower mtDNA content in breast tumor tissues compared to normal cells, which might constitute a biomarker for cancer detection. Interestingly, the same studies have demonstrated an increase of mtDNA copy number in patients with a higher risk of breast cancer. This observation inversely correlates with antioxidant levels, which may suggest increased oxidative stress levels in patients' cells with higher risk of breast cancer. In response to high oxidative stress level mtDNA production is increased [87]. Other data have shown similar dependence in EC between mtDNA mutations and an increase in mtDNA copy number as a compensatory effect $[39,88]$. A second marker which is observed in type I EC is a higher mitochondrial mass [39].

\section{Abnormal apoptotic machinery}

Apoptosis ensures normal tissue homeostasis by regulation of the balance between cell growth and death. In many human cancers, there is a deregulation of this balance. The tumor cells can avoid apoptosis through a loss of balance between anti- and pro-apoptotic proteins, reduced caspase function and impaired death receptor signaling.

There are three biochemical changes in apoptosis: activation of caspases, DNA and protein breakdown, and changes occurring in membrane recognition by phagocytic cells. In human cells apoptosis is induced via the extrinsic (death receptor) and intrinsic signaling pathway, and the intrinsic endoplasmic reticulum pathway, which is less known. It could be initiated, among others, also via genotoxic, hypoxic, oxidative stress and oncogenic signaling $[89,90]$.

The best known death receptors are: type 1 TNF receptor (TNFR1 or DR1), Fas (also known as DR2, CD95, APO-1), DR3 (Apo-3), DR4 (also known as TNF-related apoptosis inducing ligand receptor 1 TRAIL-1 or APO2), DR5 (TRAIL-2), DR6, ectodysplasin A receptor (EDAR) and nerve growth factor receptor (NGFR). These receptors possess intracellular death domains (DD) which bind with them, resulting in activation of the signaling cascade [91]. The consequence of some abnormalities in the death receptor or death domains, irrespective of the type of mechanism, is apoptosis dysregulation. For instance, studies suggest a role of reduced expression of APO-1 in the treatment of resistant leukemia and neuroblastoma cells $[92,93]$. In addition, loss of Fas and lesion of FasL, DR4, DR5, TRAIL in CIN can contribute to cervical cancer development [94].

Essential components of the intrinsic (mitochondrial) pathway are proteins of the $\mathrm{Bcl}-2$ family. The $\mathrm{BCl}-2$ family is a heterogeneous group of proteins which may promote or inhibit apoptosis by releasing pro-apoptotic factors such as BAX, BAK, BAD, BID, BCL-Xs, Bik, Bim, Hrk and anti-apoptotic factors (i.e., Bcl-2, Bcl-Xl, Bcl-W,
Bfl-1, Mcl-1) [95-97]. Bcl-2 may perform an essential and different role in neogenesis. Overexpression of the anti-apoptotic BCL-2 gene has been identified in numerous cancers including colon, thyroid, breast and endometrial cancer [98-102]. Most studies have found that low BCL-2 family gene expression could be the sign of blocking apoptosis in breast and endometrial cancer $[103,104]$. Moreover, BCL-2 gene expression is correlated with the degree of aggressiveness and differentiation in endometrial cancer. Overexpression of $\mathrm{Bcl}-2$ has also been reported to protect prostate cancer cells from apoptosis. Investigators show that overexpression of $\mathrm{Bcl}-\mathrm{xL}$ could activate multi-drug resistance in cancerous cells. The role of overexpression of Bcl-w was analyzed in colorectal adenocarcinomas as predisposing to progress from adenoma to adenocarcinoma in the colorectal epithelium. In consequence, it could be a valuable predictor of disease progression [104-107].

The third pathway of apoptosis is the intrinsic endoplasmic reticulum pathway. It is initiated by hypoxia, free radicals and glucose starvation. It is dependent on caspase 12 and mitochondrial-independent $[90,108]$.

As mentioned, caspases 2, 3, 6, 7, 8, 9, 10 play an important role in biochemical changes in apoptosis. It is believed that a low level of caspases or disturbance of their function might lead to damage of apoptosis and result in neogenesis. For instance, a low level of caspase 9 may correlate with poor prognosis in patients with stage II colorectal cancer. Positive and negative roles of caspase 3 have also been documented in carcinogenesis. It was found at a substantially decreased level in ovarian cancer [109-111], while a high level of caspase 3 could be a marker of good prognosis for treatment in lung cancer [112]. Interestingly, increased expression of caspase 3 and caspase 7 could indicate a general deregulation of apoptosis in primary breast cancer. It is unknown whether this damage of apoptosis is a primary or a secondary event in breast cancer [113]. Also, the loss of caspase- 1 mRNA and protein was observed in tumor development. This loss was correlated with pTNM stage, lymph node metastasis and poor prognosis in gastric cancer [114].

Alterations of caspase-8 gene expression including missense mutation, stop codon, deletion of leucine 62 and silencing mutations in caspase- 9 have been observed in many cancers. For instance, deletion of leucine 62 was found to be associated with the development of vulval squamous carcinoma cells. Another missense mutation (Ala-Val) at caspase-8 codon 96 and silencing mutations in the caspase- 9 gene were observed in neuroblastomas, suggesting a lack of caspase-8 expression and potential tumor suppressor role for apical caspase-9 [115-117]. The second group of caspases which is mainly related to cytokine processing during inflammatory processes comprises caspases $1,4,5,13,14$ [109]. 
Also the inhibitor of apoptosis (IAP) proteins have emerged as an important regulator of inflammation, innate immune signaling downstream and downstream inhibitor of apoptosis. It was reported that IAP proteins and X-linked IAP, XIAP in particular, were demonstrated to inhibit caspase activity $[118,119]$. It is believed that IAP members play important roles in the differentiation and proliferation of tumor cells. An increased level of IAP was detected in various human cancer and primary tumor biopsies. Moreover, IAPs are able to act as oncogenes. Accordingly, chromosome amplification of the 11q21-q23 region of c-IAP1 and c-IAP2 was found in many malignant states of cancer and esophageal squamous cell carcinomas [120].

Studies also suggest the occurrence of alterations in apoptotic genes in cancer patients. It was reported that TNF- $\alpha$ gene polymorphisms and a single nucleotide polymorphism (SNP) located in the FAS promoter region were correlated with several cancers. A protective role was detected in the association between DR4 polymorphism and bladder cancer risk and between caspase- 8 variant and breast cancer susceptibility [121-125].

One of the most common apoptotic pathways is transcription factor p53, also called tumor protein p53 or TP53 dependent. This protein is encoded by tumor suppressor gene TP53 located at chromosome 17P53, plays a role in promoting transcription of pro-apoptotic factors such as Puma, Noxa, Bax and Apaf 1, and it is also an essential player in processes of development, differentiation, cell cycle regulation, gene amplification, DNA recombination, chromosomal segregation and cellular ageing. It is also called the "guardian of the genome". In response to a spectrum of apoptotic stimuli such as oxidative stress p53 translocates to mitochondria where it displaces anti-apoptotic channel-forming proteins [126-129]. Proteins that hold bad form subunits $(\mathrm{PHB})$ are localized in the inner mitochondrial membrane. The first studies showed a role of PHB as negative cell-cycle regulators, correlation with mitochondrial proliferation and differentiation, and luteolysis in the ovary [130-132]. Subsequent research has suggested a role of PHB in the stabilization of synthesized subunits of mitochondrial respiratory enzymes and also classified it as an anti-apoptotic protein [133, 134]. Furthermore, PHB complex forms (hPhb1p and hPhb2p) are chemically induced in cancerous cells, endometrial hyperplasia and adenocarcinoma, breast cancer cell line and other cancers [135-137]. In cancer patients the PHB may be useful as a clinical marker in therapeutic strategies. In the patient's serum after cisplatin, doxorubicin or methotrexate therapy the PHB level is decreased $[138,139]$. The p53 tumor suppressor gene alterations have been correlated with most human cancers, for instance, in melanoma cells where abnormal activity of p53 contributes to the proliferation of these cells [140, 141]. Moreover, low regulation of mutant p53 expres- sion is effective in reduced cellular colony growth in cancer cells as a result of induction of apoptosis [142].

\section{Disclosure}

Authors report no conflicts of interest.

\section{References}

1. Di Mauro S, Schon EA. Mitochondrial respiratory - chain diseases. N Engl J Med 2003; 348: 2656-2668.

2. Solomon EP, Berg LR, Martin DW. Organizacja komórki. In: Solomon EP, Berg LR, Martin DW. Biologia. XXXVII wydanie polskie. MULTICO Oficyna Wydawnicza, Warszawa 2007; 66-94.

3. Kotulska A, Kucharz EJ. Miopatie mitochondrialne. Terapia 2004; 5: 43-48.

4. Wallace DC. Mitochondrial diseases in man and mouse. Science 1999; 283: 1482-1488.

5. Mannella CA. Structure and dynamics of the mitochondrial inner membrane cristae. BBA 2006; 1763: 542-548.

6. Bartnik E, Lorenc A, Mroczek K. Human mitochondria in health disease ageing and cancer. J Appl Genet 2001; 42: 65-71.

7. Fernandez-Silva P, Enriquez JA, Montaya J. Replication and transcription of mammalian mitochondria DNA. Exp Physiol 2003; 88: 41-56.

8. Newmeyer DD, Ferguson-Miller S. Mitochondria: releasing power for life and unleashing the machineries of death. Cell 2003; 112: 481-490.

9. Jaattela M. Multiple cell death pathways as regulators of tumour initiation and progression. Oncogene 2004; 23: 2746-2756.

10. Jaattela M, Cande C, Kroemer G. Lysosomes and mitochondria in the commitment to apoptosis: a potential role for cathepsin D and AIF. Cell Death Differ 2004; 11: 135-136.

11. Petros JA, Baumann AK, Ruiz-Pesini E, et al. Mt DNA mutations increase tumorogenisity in prostate cancer. Proc Natl Acad Sci USA 2005; 102: 719-724.

12. Czarnecka AM, Gammazza AM, Di Felice V. Cancer as a "Mitochondriopathy". J Cancer 2007; 3: 71-79.

13. Plak K, Czarnecka AM, Krawczyk T. Breast cancer as a mitochondria disorder (Review). Oncol Rep 2009; 21: 845-851.

14. Mates JM, Segura JA, Campos-Sandoval JA. Glutamine homeostasis and mitochondrial dynamics. Int J Biochem Cell Biol 2009; 41: 2051-2061.

15. Cairns RA, Hariss IS, Mak TW. Regulation of cancer cell metabolism. Nat Rev Cancer 2011; 11: 85-95.

16. Warburg O. On the origin of cancer cells. Science 1956; 123: 309-314.

17. Toyokuni S, Okamoto K, Yodol J, et al. Persistent oxidative stress in cancer. FEBS Lett 1995; 385: 1-3.

18. Carew JS, Huang P. Mitochondrial defects in cancer. Mol Cancer 2002; 1: 9.

19. Woods MW, Viahakls G. Anaerobic glycolysis in spontaneous and transplanted liver tumors of mice. J Natl Cancer Inst 1973; 50: 1497-1511.

20. Sanford KK, Barker BE, Parshad R, et al. Neoplastic conversion in vitro of mouse cells: cytologic chromosomal enzymatic glycolytic and growth properties. J Natl Cancer Inst 1970; 45: 1071-1096.

21. Matoba S, Kang JG, Patino WD. P53 regulates mitochondria respiration. Science 2006; 312: 1650-1653.

22. Guppy M, Leedman P, Zu X, et al. Contribution by different fuels and metabolic pathways to the total ATP turnover of proliferating MCF-7 breast cancer cells. Biochem J 2002; 364: 309-315.

23. Zu XL, Guppy M. Cancer metabolism: facts, fantasy and fiction. Biochem Biophys Res Commun 2004; 313: 459-465.

24. Halliwell B. Oxidative stress and cancer: have we moved forward? Biochem J 2007; 401: 1-11.

25. Klauning JE, Kamendulis LM. The role of oxidative stress in carcinogenesis. Annu Rev Pharmacol Toxicol 2004; 44: 239-267.

26. Kang DH. Oxidative stress, DNA damage and breast cancer. AACN Clin Issues 2002; 13: 540-549.

27. Betterigie DJ. What is oxidative stress? Metabolism 2000; 49 (2 Suppl 1): 3-8.

28. Karihtala P, Soini Y. Reactive oxygen species and antioxidant mechanisms in human tissues and their relation to malignancies. APMIS 2007; 115: 81-103. 
29. Rigoulet M, Yoboue ED, Devin A, et al. Mitochondrial ROS generation and its regulation: mechanisms involved in $\mathrm{H} 2 \mathrm{O} 2$ signaling. Antioxid Redox Signal 2010; 14: 459-468.

30. Le Bras M, Clement MV, Pervaiz S, et al. Reactive oxygen species and the mitochondrial signaling pathway of cell death. Histol Histopathol 2005; 20: 205-219.

31. Chen JQ, Brown TR, Yager JD. Mechanisms of hormone carcinogenesis: evolution of views, role of mitochondria. Adv Exp Med Biol 2008; 630: 1-18.

32. Circu ML, Aw TY. Reactive oxygen species, cellular redox systems and apoptosis. Free Radic Biol Med 2010; 48: 749-762.

33. Huang Y, Peng J, Oberley LW, et al. Transctriptional inhibition of manganese superoxide dismutase (SOD2) gene expression by DNA methylation of the 5 CpG island. Free Radic Biol Med 1997; 23: 314-320.

34. Behrend L, Henderson G, Zwacka RM. Reactive oxygen species in oncogenic transformation. Biochem Soc Trans 2003; 31: 1441-1444.

35. Fang J, Seki T, Maeda H. Therapeutic strategies by modulating oxygen stress in cancer and inflammation. Adv Drug Deliv Rev 2009; 61: 290-302.

36. Khandrika L, Kumar B, Koul S, et al. Oxidative stress in prostate cancer. Cancer Lett 2009; 282: 125-136.

37. Minelli A, Bellezza I, Conte C, et al. Oxidative stress-related aging: A role for prostate cancer? Biochim Biophys Acta 2009; 1795: 83-91.

38. Poyton RO, Ball PR, Castello PR. Miochondrial generation of free radicals and hypoxic signaling. Trends Endocrinol Metab 2009; 20: 332-340.

39. Guerra F, Kurelac I, Cormio A, et al. Placing mitochondria DNA mutations within the progression model of type I endometrial cancer. Hum Mol Genet 2011; 20: 2394-2405

40. Lin WW, Karin MA. Cytokine mediated link between innate immunity, inflammation and cancer. J Clin Invest 2007; 117: 1175-1183.

41. Ekbom A, Mc Laughlin JK, Nyren O. Pancreatitis and the risk of pancreatic cancer. N Engl J Med 1993; 329: 1502-1503.

42. Ekbom A, Helmick C, Zack M, et al. Increased risk of large-bowel cancer in Crohn's disease with colonic involvement. Lancet 1990; 336: 357 359.

43. Schetter AJ, Heegaard NH, Harris CC. Inflammation and cancer: interweaving micro RNA, free radical, cytokine and p53 pathways. Carcino genesis 2010; 31: 37-49.

44. Hussain SP, Harris CC. Inflammation and cancer: an ancient link with novel potentials. Int J Cancer 2007; 121: 2373-2380.

45. Federico A, Morgillo F, Tuccillo C, et al. Chronic inflammation and oxidative stress in human carcinogenesis. Int J Cancer 2007; 121: 2381-2386.

46. Pani G, Galeotti T, Chiarugi P. Metastasis cancer cells escape from oxidative stress. Cancer Metastasis Rev 2010; 29: 351-378.

47. Xia C, Meng Q, Liu LZ, et al. Reactive oxygen species regulate angiogenesis and tumor growth through vascular endothelial growth factor. Cancer Res 2007; 67: 10823-10830.

48. Coussens LM, Werb Z. Inflammation and cancer. Nature 2002; 420 860-867.

49. Mantovani A. Cancer: inflammation by remote control. Nature 2005; 435: 752-753.

50. Klauning JE, XU Y, Isenberg JS, et al. The role of oxidative stress in chemical carcinogenesis. Environ Health Perspect 1998; 1061: 289-295.

51. Rosin MP, Saad el Din Zaki S, Ward AJ, et al. Involvement of inflammatory reactions and elevated cell proliferation in the development of bladde cancer in schistosomiasis patients. Mutat Res 1994; 305: 283-292.

52. Trush MA, Twerdok LE, Esterline RL. Comparison of oxidant activities and the activation of benzo(a)pyrene-7, 8-dihydrodiol by polymorphonuclear leucocytes from human, rat and mouse. Xenobiotica 1990; 20 925-932.

53. Storz P. Reactive oxygen species in tumor progression. Front Biosci 2005; 10: 1881-1896.

54. Reuter S, Subash CG, Madan M, et al. Oxidative stress, inflammation, and cancer: How are they linked? Free Radic Biol Med 2010; 49: 1603-1616.

55. Baldwin AS. The NF-kappa B and I kappa B proteins: new discoveries and insights. Annu Rev Immunol 1996; 14: 649-683.

56. Schulze-Osthoff K, Ferrari D, Los M, et al. Apoptosis signaling by death receptors. Eur J Biochem 1998; 254: 439-459.

57. Giri DK, Aggarwal BB. Constitutive activation of NF-kappa B causes resistance to apoptosis in human cutaneous T cell lymphoma HuT-78 cells. Autocrine role of tumor necrosis factor and reactive oxygen intermediates. J Biol Chem 1998; 273: 14008-14014.
58. Gloire G, Legrand-Poels S, Piette J. NF-kappa B activation by reactive oxygen species: fifteen years later. Biochem Pharmacol 2006; 72: $1493-$ 1505.

59. Kundu N, Zhang S, Fulton AM. Sublethal oxidative stress inhibits tumor cell adhesion and enhances experimental metastasis of murine mammary carcinoma. Clin Exp Metastasis 1995; 13: 16-22.

60. Roebuck KA. Oxidant stress regulation of IL-8 and ICAM-1 gene expression: differential activation and binding of the transcription factors Ap-1 and NF-kappa B (Review). Int J Mol Med 1999; 4: 223-230.

61. Westermarck J, Kahari VM. Regulation of matrix metalloproteinase expression in tumor invasion. FASEB J 1999; 13: 781-792.

62. North S, Moenner M, Bikfalvi A. Recent developments in the regulation of the angiogenic switch by cellular stress factors in tumors. Cancer Lett 2005; 218: 1-14.

63. Longo R, Sarmiento R, Fanelli $M$, et al. Anti-angiogenic therapy: rationale, challenges and clinical studies. Angiogenesis 2002; 5: 237-256.

64. Alon T, Hemo I, Itin A, et al. Vascular endothelial growth factor acts as a survival factor for newly formed retinal vessels and has implications for retinopathy of prematurity. Nat Med 1995; 1: 1024-1028.

65. Eatock MM, Schatzlein A, Kaye SB. Tumor vasculature as a target for anticancer therapy. Cancer Treat Rev 2000; 26: 191-204.

66. Anderson S, Bankier AT, Barrell BG, et al. Young sequence and organization of the human mitochondrial genome. Nature 1981; 290: 457-465.

67. Wallace DC. Mitochondrial DNA sequence variation in human evolution and disease. Proc Natl Acad Sci USA 1994; 91: 8739-8746.

68. Liu VW, Shi HH, Cheung AN, et al. High incidence of somatic mitochondrial DNA mutations in human ovarian carcinomas. Cancer Res 2001; 61: 5998-6001.

69. Czarnecka AM, Golik P, Bartnik E. Mitochondrial DNA mutations in human neoplasia. J Appl Genet 2006; 47: 67-78.

70. http://www.mitomap.org/pub/MITOMAP/MitomapFigures/mitomapgenome.pdf

71. Lee $\mathrm{HC}$, Yin $\mathrm{PH}$, Lin JC, et al. Mitochondrial genome instability and mtDNA depletion in human cancers. Ann N Y Acad Sci 2005; 1042: 109-122.

72. Zhao YB, Yang HY, Zhang XW, et al. Mutation in D-loop region of mitochondrial DNA in gastric cancer and its significance. World J Gastroenterol 2005; 11: 3304-3306.

73. Liu VWS, Yang HJ, Wang Y, et al. High frequency of mitochondrial genome instability in human endometrial carcinomas. Br J Cancer 2003; 89: 697-701.

74. Bai RK, Leal SM, Covarrubias D, et al. Mitochondrial genetic background modifies breast cancer risk. Cancer Res 2007; 67: 4687-4694.

75. Liu VW, Wang Y, Yang HJ, et al. Mitochondrial DNA variant 16189T>C is associated with susceptibility to endometrial cancer. Hum Mutant 2003; 22: 173-174.

76. Czarnecka AM, Klemba A, Semczuk A, et al. Common mitochondria polymorphisms as risk factor for endometrial cancer. Int Arch Med 2009; 2: 1-12.

77. Altshuler D, Daly MJ, Lander ES. Genetic mapping in human disease. Science 2008; 322: 881-888.

78. Canter JA, Kallianpur AR, Parl FF, et al. Mitochondrial DNA G10398A polymorphism and invasive breast cancer in African-American women. Cancer Res 2005: 65: 8028-8033.

79. Masayesva BG, Mambo E, Teylor RJ, et al. Mitochondrial DNA content increase in response to cigarette smoking. Cancer Epidemiol Biomark ers Prev 2006; 15: 19-24

80. Tan D, Goerlitz DS, Dumitrescu RG, et al. Associations between cigarette smoking and mitochondrial DNA abnormalities in buccal cells. Carcinogenesis 2008; 29: 1170-1177.

81. Salas A, Carracedo A, Macaulay V, et al. A practical guide to mitochondrial DNA error prevention in clinical, forensic, and population genetics. Biochem Biophys Res Commun 2005; 335: 891-899.

82. Pezzotti A, Kraft P, Hankinson SE, et al. The mitochondrial A10398G polymorphism, interaction with alcohol consumption, and breast cancer risk. PLoS One 2009; 4: 5356

83. Wallace DC. A mitochondrial paradigm of metabolic and degenerative diseases, aging, and cancer: a dawn for evolutionary medicine. Annu Rev Genet 2005; 39: 359-407.

84. Czarnecka AM, Krawczyk T, Zdrożny M, et al. Mitochondrial NADH-dehydrogenase subunit 3 (ND3) polymorphism (A10398G) and sporadic breast cancer in Poland. Breast Cancer Res Treat 2010; 121: 511-518. 
85. Czarnecka AM, Kukwa W, Krawczyk T, et al. Mitochondrial DNA mutations in cancer - from bench to bedside. Front Biosci 2010; 15 437-460.

86. Chatterjee A, Mambo E, Sidransky D. Mitochondrial DNA mutations in human cancer. Oncogene 2006; 25: 4663-4674.

87. Shen J, Platek M, Mahasnch A, et al. Mitochondrial copy number and risk of breast cancer: a pilot study. Mitochondrion 2010; 10: 62-68.

88. Cormio A, Guerra F, Cormio G, et al. The PGC-1 alfa-dependent pathway of mitochondrial biogenesis is upregulated in type I endometria cancer. Biochem Biophys Res Commun 2009; 390: 1182-1185.

89. Kumar V, Abbas AK, Aster JC, et al. Cellular responses to stress and toxic insults: adaptation, injury and death. In: Robbins S, Cotran R. Pathologic basis of disease. 8 ed. Saunders Elsevier, Philadelphia 2010; 25-32.

90. O'Brien MA, Kirby R. Apoptosis: a review of pro-apoptotic and antiapoptotic pathways and dysregulation in disease. J Vet Emerg Crit Care 2008; 18: 572-585.

91. Lavrik I, Golks A, Krammer PH. Death receptor signaling. J Cell Sci 2005; 118: 265-267

92. Friesen C, Fulda S, Debatin KM. Deficient activation of the CD95 (APO 1/Fas) system in drug resistant cells. Leukaemia 1997; 11: 1833-1841.

93. Fulda S, Los M, Friesen C, et al. Chemosensitivity of solid tumour cells in vitro is related to activation of the CD95 system. Int J Cancer 1998 76: $105-114$.

94. Reesink-Peters N, Hougardy BM, van den Heuvel FA, et al. Death receptors and ligands in cervical carcinogenesis: an immunohistochemical study. Gynaecol Oncol 2005; 96: 705-713.

95. Antonsson B, Martinou JC. The Bcl-2 proteins family. Exp Cell Res 2000; 256: 50-57.

96. Chao DT, Korsmeyer SJ. BCL-2 family: regulators of cell death. Annu Rev Immunol 1998; 16: 395-419.

97. Green DR. Apoptosis. Death deceiver. Nature 1998; 396: 629-630.

98. Reed JC. BCl-2 family proteins: regulators of apoptosis and chemoresistance in haematologic malignancies. Semin Haematol 1997; 34: 9-19.

99. Bukholm IK, Nesland JM. Protein expression of p53, p21 (WAF1/CIP1) bcl-2, Bax, cyclin D1 and pRb in human colon carcinomas. Virchows Arch 2000; 436: 224-228.

100. Linjawi A, Kontogiannea M, Halwani F, et al. Prognostic significance of p53, bcl-2, and Bax expression in early breast cancer. J Am Coll Surg 2004; 198: 83-90

101. Pappa G, Lichtenberg M, lori R, et al. Comparison of growth inhibition profiles and mechanisms of apoptosis induction in human colon can cer cell lines by isothiocyanates and indoles from Brassicaceae. Mutat Res 2006; 599: 76-87.

102. Soda G, Antonaci A, Bosco D, et al. Expression of bcl-2, cerbB-2, p53, and p21 (waf1-cip1) protein in thyroid carcinomas. J Exp Clin Cance Res 1999; 18: 363-367.

103. Fernandez Y, Gu B, Martinez A, et al. Inhibition of apoptosis in human breast cancer cells: role in tumor progression to the metastatic state. Int J Cancer 2002; 101: 317-326.

104. Vaskivuo TE, Stenback F, Tapanainen JS. Apoptosis and apoptosis related factors Bcl-2, Bax, tumor necrosis factor-alfa, and NF-kappa $B$ in human endometrial hyperplasia and carcinoma. Cancer 2002; 95: 1463-1471

105. Bozdogan O, Atasoy P, Erekul S, et al. Apoptosis-related proteins and steroid hormone receptors in normal, hyperplastic, and neoplastic endometrium. Int J Gynecol Pathol 2002; 21: 375-382.

106. Geisler JP, Geisler HE, Wiemann MC, et al. Lack of bcl-2 persistance: an independent prognostic indicator of poor prognosis in endometria carcinoma. Gynecol Oncol 1998; 71: 305-307.

107. Lee HW, Lee SS, Lee SJ, et al. Bcl-w is expressed in a majority of infiltrative gastric adenocarcinomas and suppresses the cancer cell death by blocking stress-activated protein kinase/c-Jun NH2-terminal kinase activation. Cancer Res 2003; 63: 1093-1100.

108. Szegezdi E, Fitzgerald U, Samali A. Caspase 12 and ER stress mediated apoptosis: the story so far. Ann NY Acad Sci 2003; 1010: 186-194.

109. Fink SL, Cookson BT. Apoptosis, pyroptosis, and necrosis: mechanistic description of dead and dying eukaryotic cells. Infect Immun 2005 73: 1907-1916

110. Shen XG, Wang C, Li Y, et al. Down regulation of caspase 9 is a frequent event in patients with stage II colorectal cancer and correlates with poor clinical outcome. Colorectal Dis 2010; 12: 1213-1218.
111. Devarajan E, Sahin AA, Chen JS, et al. Down-regulation of caspase 3 in breast cancer: a possible mechanism for chemoresistance. Oncogene 2002; 21: 8843-8851.

112. Koomagi R, Volm M. Relationship between the expression of caspase- 3 and the clinical outcome of patients with non-small cell lung cancer. Anticancer Res 2000; 20: 493-496.

113. Grigoriev MY, Pozharissky KM, Hanson KP, et al. Expression of caspase-3 and -7 does not correlate with the extent of apoptosis in primary breast carcinomas. Cell Cycle 2002; 1: 337-342.

114. Jee CD, Lee HS, Bae SI, et al. Loss of caspase-1 gene expression in human gastric carcinomas and cell lines. Int J Oncol 2005; 26: 1265 1271

115. Takita J, Yang HW, Chen YY, et al. Allelic imbalance on chromosome $2 q$ and alterations of the caspase 8 gene in neuroblastoma. Oncogene 2001; 20: 4424-4432.

116. Liu B, Peng D, Lu Y, et al. A novel single amino acid deletion caspase-8 mutant in cancer cells that lost proapoptotic activity. J Biol Chem 2002; 277: 30159-30164.

117. Catchpoole DR, Lock RB. The potential tumour suppressor role for caspase-9 (CASP9) in the childhood malignancy, neuroblastoma. Eur J Cancer 2001; 37: 2217-2221.

118. Eckelman BP, Salvesen GS. The human anti-apoptotic proteins CIAP1 and CIAP2 bind but do not inhibit caspase. J Biol Chem 2006; 281: 3254-3260.

119. Damgaard RB, Gyrd-Hansen M. Inhibitor of apoptosis (IAP) proteins in regulation of inflammation and innate immunity. Discov Med 2011; 11: 221-231.

120. Uren AG, O'Rourke K, Aravind LA, et al. Identification of paracaspases and metacaspases: two ancient families of caspase-like proteins, one of which plays a key role in MALT lymphoma. Mol Cell 2000; 6: 961967.

121. Balkwill F. Tumor necrosis factor or tumor promoting factor? Cytokine Growth Factor Rev 2002; 13: 135-141.

122. Lai HC, Sytwu HK, Sun CA, et al. Single nucleotide polymorphism at Fas promoter is associated with cervical carcinogenesis. Int J Cancer 2003; 103: 221-225.

123. Sun T, Miao X, Zhang $X$, et al. Polymorphisms of death pathway genes FAS and FASL in esophageal squamous-cell carcinoma. J Natl Cancer Inst 2004; 96: 1030-1036.

124. Hazra A, Chamberlain RM, Grossman HB, et al. Death receptor 4 and bladder cancer risk. Cancer Res 2003; 63: 1157-1159.

125. Mac Pherson G, Healey CS, Teare MD, et al. Association of a common variant of the CASP8 gene with reduced risk of breast cancer. J Natl Cancer Inst 2004; 96: 1866-1869.

126. Galluzzi L, Morselli E, Kepp O, et al. Mitochondrial liaisons of p53. Antioxid Redox Signal 2010; 15: 1691-1714.

127. Levine AJ, Momand J, Finlay CA. The p53 tumour suppressor gene. Nature 1991; 351: 453-456.

128. Oren M, Rotter V. Introduction: p53 - the first twenty years. Cell Mol Life Sci 1999; 55: 9-11.

129. Lane DP. P53, guardian of the genome. Nature 1992; 358: 15-16.

130. Coates PJ, Jamleson DJ, Smart K, et al. The prohibitin family of mitochondrial proteins regulate replicative lifespan. Curr Biol 1997; 7: 607-610.

131. Ikonen E, Fledier K, Parton RG, et al. Prohibitin an antiproliferative protein, is localized to mitochondria. FEBS Lett 1995; 385: 273-277.

132. Thompson WE, Branch A, Whittaker JA, et al. Characterization of prohibitin in a newly established rat ovarian granulose cell line. Endocrinology 2001; 142: 4076-4085

133. Nijtmans LGJ, De Jong L, Sanz MA, et al. Prohibitin acts as a membrane-bound chaperone for the stabilization of mitochondrial proteins. EMBO J 2000; 19: 2444-2451.

134. Coller HA, Khrapko K, Bodyak ND, et al. High frequency of homoplasmic mitochondrial DNA mutations in human tumors can be explained without selection. Nat Genet 2001; 28: 147-150.

135. Nijtmans LGJ, Sanz MA, Coates PJ. The mitochondrial PHB complex: roles the mitochondrial respiratory complex assembly, ageing and degenerative disease. Cell Mol Life Sci 2002; 59: 143-155.

136. Byrjalsen I, Larsen PM, Fey SJ, et al. Two-dimensional gel analysis of human endometrial proteins: characterization of proteins with increased expression in hyperplasia and adenocarcinoma. Mol Hum Reprod 1999; 5: 748-756. 
137. Williams K, Chubb C, Huberman E, et al. Analysis of differential protein expression in normal and neoplastic human breast epithelial cell lines. Electrophoresis 1996; 19: 333-343.

138. Mengwasser J, Plau A, Schiag P, et al. Differential immunization identifies PHB1/PHB2 as blood borne tumor antigens. Oncogene 2004; 23 : 7430-7435.

139. Fellenberg J, Dechant MJ, Ewerbeck V, et al. Identification of drug-regulated genes in osteosarcoma cells. Int J Cancer 2003; 10: 636-643.

140. Bai L, Zhu WG. P53: structure, function and therapeutic applications. J Cancer Mol 2006; 2: 141-153.
141. Avery-Kiejda KA, Bowden NA, Croft AJ, et al. P53 in human melanoma fails to regulate target genes associated with apoptosis and the cell cycle and may contribute to proliferation. BMC Cancer 2011; 11: 203.

142. Vikhanskaya F, Lee MK, Mazzoletti M, et al. Cancer-derived p53 mutants suppress p53 target gene expression-potential mechanism for gain of function of mutant p53. Nucleic Acids Res 2007; 35: 2093 2104 